\title{
Research and Construction of Learning Community Model Based on Social Network Services
}

\author{
Liang $\mathrm{Hu}$ \\ Department of humanities and management, JiangXi Police College, NanChang, China
}

\begin{abstract}
In view of the current lack of mutual exchanges and mutual learning problems in the learning process Chinese college students, this paper presents SNS network learning community model and construction method based on analysis the students' learning interest in the same data, the students are divided into a community group, provide a good interactive environment for collaboration between students at the same time learning, network learning students can solve the problems in the process of communication.
\end{abstract}

Keywords-learning community; social network services; internet

\section{INTRODUCTION}

Social Network Services is based on Web2.0 derived from a personal as the center of social networking services, which allows users to share ideas, activities, events, events, in a personal relationship network[1]. As SNS value sharing and interaction, respect for the user's personality, allowing users to unlimited expansion of interpersonal relationships, so it is popular in the world in the short term. The Pew Internet and American life project research shows that as of 2008, American adults have SNS registered account number increased from $8 \%$ in 2008 to $35 \%$ in 2005. Another study shows that nearly 55\% of young people use social networking services every day to contact friends, to meet new friends, to share personal information and resources. In recent years, the country is also popular micro-blog, everyone, happy network and other SNS sites[2][3]. It is precisely because of the wide use of social network services in young people, and their attention to the positive interaction between the user and the characteristics of cooperation, so that we see a broad space for SNS application in education. Further research on the educational application of SNS is the objective requirement of the socialization of the network education.

SNS is one of the most popular Web2.0 technologies and applications in, have unique advantages and good prospects in the network teaching, the idea of SNS into the network teaching, can create a communication, collaboration and sharing resources learning environment for students[4][5]. It is a hot issue in the field of educational technology that how to use the advantages of SNS to construct the network learning community to effectively carry out the network learning. Although SNS has been applied to the network teaching point of view has been put forward by many scholars, but most directly copy the SNS website to build "entity" network learning community[6]. This paper introduce SNS network teaching platform at the same time, focus on the construction methods of e-learning community a dynamic "interest", according to the actual learning behavior of students' interest in the same dynamic divided into the same group, so as to provide a good environment for learning interactive collaboration between students learning.

\section{LEARNING COMMUNITY MOdEL BASED ON SNS}

SNS emphasizes human centered, advocating "sharing, interactive and collaborative interpersonal" concept, everyone in the SNS not only can fully demonstrate their own unique personality, but also can interact and collaborate with others, create and share a large number of effective resources, in order to help people to expand and maintain the interpersonal relationship, eventually forming a with the common characteristics and the common goal of the group[7].

It can successfully build a learning community in the traditional network platform, but this often cannot meet the personalized needs of community members, they discuss and exchange is only limited to a single problem or resource, as shown in Figure 1, members can not form a true sense of the learning community, so I want to expand contribute to the learning community network is more difficult.

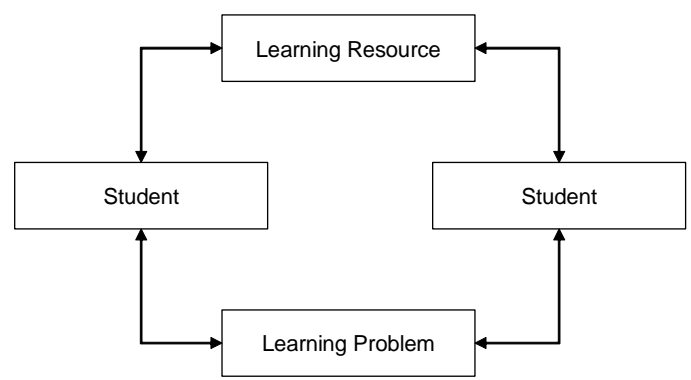

FIGURE I. BASIC MODEL OF NETWORK LEARNING COMMUNITY

Constructing the network learning community can make up for the shortcomings of traditional construction by SNS, in the learning community based on the basic structural unit of SNS, members can own learning needs as the center, abide by the learning community in all kinds of standard system, through problems, as shown in Figure 2, resources and activities with other members to establish an interactive information flow, and these interactions can also continue to attract more members to join, eventually forming a continuous expansion and extension of the network learning community. 


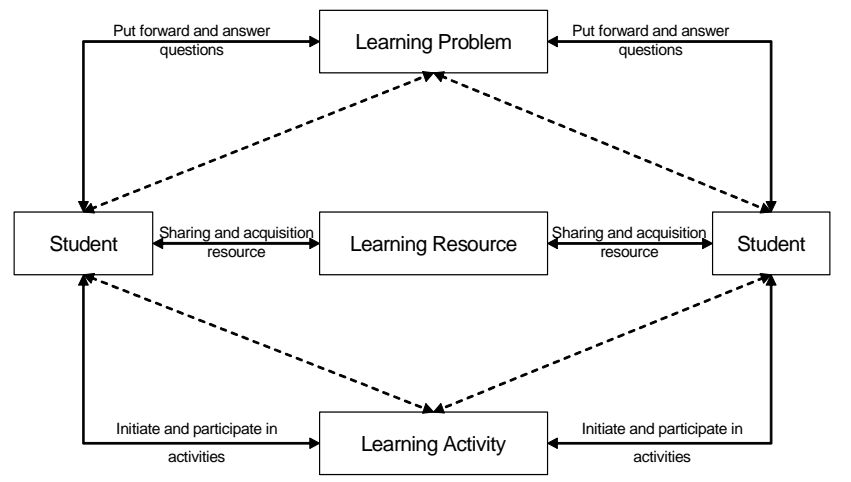

FIGURE II. NETWORK LEARNING COMMUNITY MODEL BASED ON SNS

\section{CONSTRUCTION OF NETWORK LEARNING COMMUNITY}

Because the network of learners of knowledge background is different, but very scattered, they will gather together to form a group with the same learning community interests, is a key issue to be solved. The construction of learning community mainly solves how to automatically cluster the members with the same or similar interests in the same community, and automatically adjust the structure of the community according to the dynamic behavior of the members. Because there is no dynamic behavior data of members in the system of community building, it is necessary to initialize the system. With the continuous learning of the members, the system to collect a large number of members of the data, then it can be based on the interest of these dynamic data mining. At the same time as the members of the interest is not immutable and frozen, so the system needs to find members of the same or similar interest, they will be together again to form a community, that community agencies can make timely changes according to the interests of the members of the adaptability change. The construction process of the learning community is shown in Figure 3:

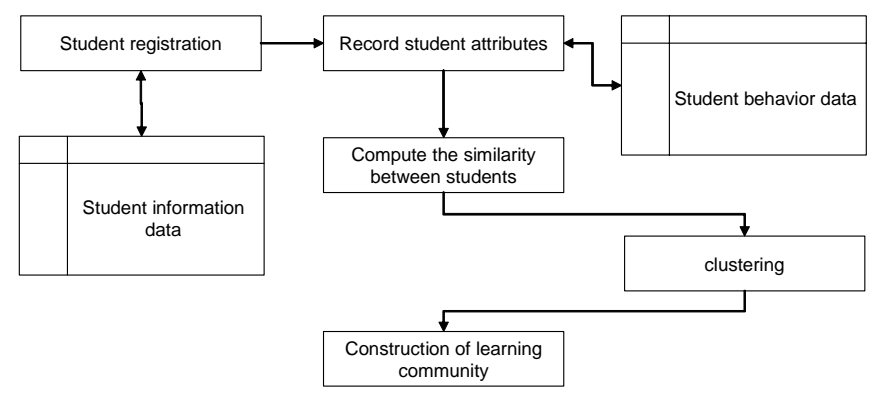

FIGURE III. CONSTRUCTION PROCESS OF NETWORK LEARNING COMMUNITY

\section{A. Common Ground between Students}

During the learning process, the members can browse or download the courseware, ask questions, participate in the discussion and so on, which can be expressed as a request for a resource, which represents the interests and intentions of the members. Here the definition of the interests of the students for the assessment of a teaching resource value, evaluation value is higher that the member of this resource more interested, and if the two students are always on the related resources with similar evaluation value, so that the two members may have similar interests. By members of the access frequency of a resource, access time and other learning data to implicit access to the assessment value, and can objectively reflect the interests of students.

\section{B. Interest Degree}

Web log mining is currently popular data mining method, through the analysis of members in a period of time on the page browsing data, and you can calculate the members of a certain degree of interest in the resources. Sun is proposed based on the number of visits and the degree of interest in browsing time normalization algorithm to measure the interests of the members: a number of members of the browser page for Freq $(\mathrm{Pi})$, the $\mathrm{j}$ time browsing time is Time $(\mathrm{Pi}, \mathrm{j})$, members of the PI page interest degree is Interest $(\mathrm{Pi})$. The total time to browse the members page is Time( $\mathrm{Pi}, \mathrm{j})$.

Assume that members from the list of the query page list of the CPC to click on the page, this paper constitute the first click on the page set $\mathrm{T}$. You can put all the pages in $\mathrm{T}$ total viewing time as a series of average value and standard deviation were calculated at the same time of the sequence, and then use the Gauss formula of normalized processing, sequence of each number in the range [-1,1] probability is about $99 \%$, and then through the translation operation to Interest(Pi) falls in $[0,1]$. Page interest degree formula is as follows:

$$
\operatorname{Interest}\left(P_{i}\right)=\frac{\sum \operatorname{Time}\left(P_{i}, j\right)-\mu+3 \delta}{6 \delta}
$$

\section{Interest Similarity Degree}

In order to gather the same or similar members together, we must first measure the similarity between them, and then select some members of the highest similarity as the nearest neighbors of the members. Therefore, how to take the similarity measure of interest is the key to improve the accuracy of cluster grouping. The cosine similarity interest scale different members did not consider the measure method, this paper uses the modified cosine similarity algorithm, by subtracting the members of the "average interest degree to improve this defect. Let member $\mathrm{X}$ and member y common browsing web collection with $\mathrm{P}(\mathrm{x}, \mathrm{y})$ said, $\mathrm{P}(\mathrm{x})$ and $\mathrm{P}(\mathrm{y})$ respectively, expressed by members of the $\mathrm{X}$ and member $\mathrm{y}$ browsing the collection of pages, the members of $\mathrm{X}$ and member y similarity between the calculation method is as follows:

$$
\operatorname{Sim}(x, y)=\frac{\sum\left(\operatorname{Interest}\left(p_{x}\right)-x\right)\left(\operatorname{Interest}\left(p_{y}\right)-y\right)}{\sqrt{\sum\left(\operatorname{Interest}\left(p_{x}\right)-x\right)^{2} \sqrt{\sum\left(\operatorname{Interest}\left(p_{y}\right)-y\right)^{2}}}}
$$

\section{Construction al Gorithm of Learning Community}

The learning community should be a group with the same or similar interests, so the establishment of the learning community should be as far as possible to the members of 
interest similarity in the same community group. Under the guidance of this idea, the construction algorithm of learning community is as follows:

Step 1 Compute the interest similarity among all members according to the formula.

Step 2 Set a specific threshold value T1, calculate the correlation of each member that determined by the number of members of the high degree of similarity of the number of members to determine the level of correlation. The total number of members of the network learning hypothesis in $\mathrm{N}$, related to the members of the formula:

$$
\theta_{i}=\frac{\sum a_{i j}}{N}
$$

Step 3 Select one member of the highest correlation and establish the community as the center of a community group. In advance, a threshold value T2 is set, if a member of the center member of the community is higher than the threshold value, then the member is put into the community.

Step 4 The rest of the member in accordance with the steps 1 to 3 of the order, repeated calculation, matching, until the remaining members of the highest correlation is lower than a specific threshold T0. For members of the concentration lower than T0, the similarity between them and the members of the learning community were calculated to enter the most similar learning community.

\section{DISCUSSION AND FUTURE WORK}

SNS in the construction of network learning environment has a great advantage, so take advantage of SNS to construct the network learning community, and create a learner's exchanging and sharing of resources, equality and mutual benefit learning environment. Because the number of students to participate in the network to learn a large number of different interests and hobbies, in the learning process will inevitably occur in the exchange of students. Therefore, this paper proposes a SNS based network learning community construction method, which is based on students' learning behavior analysis and dig out the interest in learning, and their dynamic division of learning community groups, learning community structure to maintain stability.

\section{ACKNOWLEDGMENT}

This author's work is supported by JiangXi Research on teaching reform of higher education(JXJG-15-19-3), JiangXi Science and technology research project of Education Department(GJJ151193), JiangXi Social Science Planning Projects during the 12th Five-Year Plan(14TQ05), JiangXi University Party Building Project(JXGXDJKT.QN-201665) and JiangXi Police College Scientific Research Project(2014QN001).

\section{REFERENCES}

[1] Yang Honggang, Ning Yuwen Gao Donghuai, et al. The Construction of SNS based Network Learning Community[J]. Modern Educational Technology, 2010, 20(5): 93-96. (in Chinese)

[2] Yu. Study on online learning community students methodology course teaching mode exploration[J]. Degree and Graduate Education, 2016,04:12-17. (in Chinese)

[3] Gu. On the construction of community social networks and online learning mode[J]. Continuing Education Research, 2016,01:13-15. (in Chinese)

[4] Li Jun.. Occupation construction model of the remote network learning community[J]. Education and Occupation Education, 2016,08:103-105. (in Chinese)

[5] Yan Zhijun, Yang Lina, Meng Zhaokuan. Virtual community learning community based on the idea of personalized recommendation[J]. Modern Educational Technology, 2012,01:88-92. (in Chinese)

[6] Liu. Study on the construction of teachers' network learning community based on agent[J] Chinese Distance Education, 2011,12:77-80. (in Chinese)

[7] Zhang Bo, Zhang Deming. Study on the construction of learning community in knowledge alliance[J]. Journal of information science, 2010,05:32-36. (in Chinese)

[8] Shao Jie. The effective construction of classroom learning community -a case study of advanced language programming (VB) curriculum[J]. Modern Educational Technology, 2009,08:120-124. (in Chinese) 